\title{
AIDS at Christmas time
}

\section{The end of 2005 was supposed to mark the achievement of a critical goal in the treatment of HIV in poor countries. The goal hasn't been met, but it is now within sight.}

\rceil wo years ago, the United Nations and the World Health Organization (WHO) launched the 3 By 5 Initiative for the global treatment of HIV, with the aim of providing 3 million people in developing countries with antiretroviral drugs by the end of 2005 . This ambitious target will not quite be met, with the number falling short by at least a million. But there has been a great advance on the 400,000 who were receiving treatment at the end of 2003 . That momentum must be sustained into the new year.

Continued progress will depend on strong political leadership in the countries hardest hit by AIDS, as well as on cash support from outside. The issue of drug pricing has become less acute, as mechanisms have been established to supply HIV treatments at a reasonable cost. But more than 4 million additional patients need the drugs now and tens of millions more will eventually require them.

The initiative set specific national targets, and these have already been met in some middle-income countries; poorer countries are having more trouble, on account of the chronic weakness of their public-health systems. But even here there are grounds for hope. Malawi, for example, has increased the number of its people who are receiving antiretroviral treatment from just 4,000 in 2003 to about 36,000 . With more cash support, its programmes can expand to reach the estimated 100,000 other Malawians who still need antiretroviral therapy.

Elsewhere, leaders have overcome cultural barriers and the stigma of AIDS: the prime minister of Lesotho, for example, was tested for HIV in public. And since Brazil initiated free treatment in 1996, deaths from AIDS-related hospitalizations have declined by fourfifths. Yet in too many regions of the world, drug availability remains chronically inadequate. Against the successes of nations such as Malawi and Brazil must be set the failures of others, including three countries with some of the biggest AIDS crises of all: South Africa, Nigeria and India.

South Africa is one of the wealthiest countries on the African continent, but less than a fifth of the nearly 700,000 people who need drugs are receiving them. Manto Tshabalala-Msimang, the country's health minister, meanwhile continues to emphasize herbal remedies, most recently in a speech in Durban on 1 December.

In Nigeria, an inept and corrupt bureaucracy has severely impeded the roll-out of treatment, which remains out of reach for the overwhelming bulk of the estimated 500,000 people who need it. The government has failed to substantially boost health spending, despite recent windfall revenues from oil exports.

And in India, which may be on the brink of an explosive HIV epidemic, access to treatment has been slow to improve and government officials have been reluctant to face up to the likely extent of the problem. Prime Minister Manmohan Singh has at least shown some leadership in this regard, calling earlier this month for people to shed traditional inhibitions about discussing sex and to address the threat head on.

Next spring, the WHO will

"Effective HIV treatment can be widely introduced and administered, even in the poorest countries."

set revised targets for access to the medicines, as it moves towards its existing goal of 'universal access' to appropriate therapies by 2010 - a goal endorsed by world leaders last July at the G8 meeting at Gleneagles in Scotland. But for that to happen, the world's richest nations need to provide money, particularly for the Global Fund to Fight AIDS, Tuberculosis and Malaria, which has so far raised only $\$ 3.7$ billion of the $\$ 7$ billion that it would like to spend by 2007 . Major corporations should also contribute directly to the Global Fund - an approach endorsed recently by the Global Business Coalition on HIV/AIDS, whose members include British American Tobacco and Anglo American.

Only a few years ago, antiretrovirals cost thousands of dollars per patient and widespread doubts persisted about their efficacy in places that lacked a good public-health infrastructure. The goal of universal access seemed wildly remote. This Christmas, it seems much closer. Effective HIV treatment can be widely introduced and administered, even in the poorest countries. The world must move forward rapidly towards universal access.

\section{A poor assessment}

\section{Given Japan's strong scientific record, the country has a badly flawed research evaluation system.}

$\mathrm{n}$ the next few weeks, the government of Japan will announce its budget for the fiscal year starting in April 2006. The slow economy and tight overall budget situation may finally have caught up with research, and this year, for the first time in fifteen years, science spending could be cut.
Economies and budgets wax and wane, and scientists cannot expect increased funds as a birthright. But they do have a right to expect fair and transparent evaluation as a guide to good budget management. Japan's national system is letting them down. For decades after the Second World War, spending on science was distributed evenly among about a hundred national universities. But since the mid-1990s, Japan has taken a more selective approach, as befits one of the world's leading scientific powers.

The Council for Science and Technology Policy was established in 2001 to advise the prime minister. Its 15 -member council, chaired by the prime minister and including five other ministers of state, 